\title{
ESPACIOS DE DIVULGACIÓN CIENTÍFICA DENTRO DE LA TELEVISIÓN DE SERVICIO PÚBLICO: UN ESTUDIO DE CASO
}

\author{
SCIENTIFIC DIVULGATION SPACES IN PUBLIC SERVICE \\ TELEVISION: A CASE STUDY
}

AUTOR

Luis Javier Martínez Rolán

Universidade de Santiago de Compostela (España)

xabier.rolan@gmail.com

\section{RESUMEN}

El paradigma de la televisión de calidad parece desnortado en estos momentos televisivos actuales. Los cambios regulativos desvirtúan la función de "servicio público" de la televisión, restándole cada vez más importancia y relegándola a un segundo plano a nivel cualitativo en pro de una importancia de los elementos cuantitativos (minutos de publicidad, por ejemplo) en la legislación transversal.

Sin embargo, algunas televisiones públicas otorgan un voto de confianza a apuestas de programación diferentes. Ciencianosa es un ejemplo de formato televisivo de divulgación científica en una televisión pública regional que conjuga entretenimiento y formación de forma armónica. 


\section{PALABRAS CLAVE}

Televisión - Servicio Público - Divulgación científica.

\section{ABSTRACT}

The paradigm of quality on tv nowadays seems to be out of itself. Current tv changes in laws undermined the role of "public service" of television, being less important, in qualitative terms, than the quantitative elements (minutes of advertisement, for example) in the transverse legislation.

However, some public television stations give a vote of confidence in different programming tv formats. Ciencianosa is an example of scientific divulgation tvn format in a regional public television that combines entertainment and education in harmony.

\section{KEY WORDS}

Television - Public service- Scientific divulgation.

\section{ÍNDICE}

1. Introducción.

2. El servicio público de la televisión. Breve aproximación.

3. La televisión autonómica gallega. La TVG.

\subsection{Legislación.}

4. Contenidos de calidad en la TVG. Un ejemplo de divulgación científica.

4.1. Ciencianosa y el mundo científico gallego.

4.2. Ciencianosa como parte de la programación de servicio público.

5. Conclusiones.

6. Bibliografía.

7. Webgrafía. 


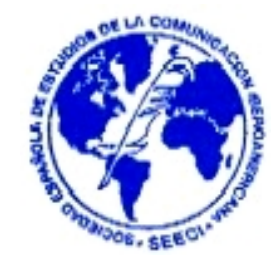

\section{Introducción}

En un contexto mediático como el actual, caracterizado por el cambio constante de sus procesos y estructuras, la televisión continúa posicionándose como el principal medio de comunicación. Una hegemonía marcada por su gran implantación (cuenta con una penetración del $88,6 \%{ }^{1}$ ) consumo diario (217 minutos por habitante y día ${ }^{2}$ ) y -por tanto- que postula a la televisión como el media con mayor injerencia en el proceso de socialización de la persona.

La relevancia que adquiere el medio audiovisual para la sociedad ha propiciado que, desde su inicio, haya sido tratado como un servicio público y, por tanto, que sea el estado el encargado de velar por la calidad de sus contenidos. Una calidad que, además de referirse a la idoneidad de los contenidos vehiculados por el medio, también se relaciona con la estructuración de su programación en torno a las clásicas máximas de: formar, informar y entretener.

Con la liberación del sector audiovisual, acontecida en la década de los 80 , que tuvo como resultado el incremento de la oferta televisiva, dio inicio un proceso de deformación de los contenidos. Proceso que ha derivado en una crisis de la concepción de la televisión como servicio público, así como en una mayor preocupación por su preservación (Comisión 2001).

El objeto del presente trabajo es realizar una aproximación a la noción del servicio público de la televisión, en particular a los contenidos de carácter educativo, a partir del análisis de "Ciencia Nosa" un programa de divulgación científica de la Televisión de Galicia.

\footnotetext{
${ }^{1}$ AIMC (2006): Resumen del Estudio General de Medios. Disponible en www.aimc.es/-Datos-EGM-Resumen-General-.html.

2 GRUPO CORPORACIÓN MULTIMEDIA (2007): "La audencia en televisión en 2006" Disponible en http://200.2.115.237/IMG/pdf/anual 2006 final.pdf. Consultado el 02/01/2007.
} 


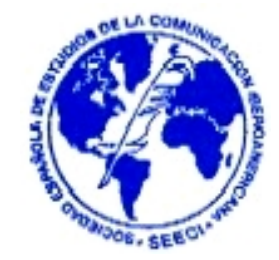

\section{El servicio público de la televisión. Breve aproximación.}

Dentro panorama mediático actual, el servicio público de la televisión continúa siendo una de las cuestiones que suscitan mayor controversia dada la falta de precisión que presenta su definición. Jorge del Corral (2005, pág. 60) destaca que la complejidad en la definición del servicio público de televisión se hizo patente en el mismo momento en el que se quiso romper el monopolio de Radio Televisión Española (RTVE).

"La falta de una definición de servicio público de la televisión, supuso, en el momento de la apertura del monopolio, el planteamiento de una serie de problemas diversos. La mayoría de ellos derivan de la orientación comercial que, paulatinamente, ha ido adoptando la televisión pública, y del hecho de que su financiación no se haya limitado a producciones de servicio público". (Del Corral 2005, pág. 60).

Siguiendo a Gorostiaga (1982), la definición del servicio público de la se puede estructurar en función de cuatro características: su titularidad estatal, el hecho de estar dirigida hacia un público, el constituir una pieza indispensable para la vida social y su independencia respecto el poder político.

1. La televisión es servicio público en cuanto que se trata de una actividad estatal cuya titularidad asume el Estado. Precisamente, en ejercicio de dicha titularidad, es el Estado el que debe velar por la calidad de dicho servicio.

2. Es una actividad cuyo destinatario es el público. La concepción del servicio público está vinculada, desde su origen, a planteamientos utilitaristas, enfocados a satisfacer una necesidad de la ciudadanía. Planteamientos que tratan de regular la maximización del bienestar en la mayoría de la población, 
particularmente si se parte del hecho de que: los media transmiten información, ayudan a la configuración de la opinión pública y, tal como se ha demostrado, favorecen la cohesión social.

3. Se configura como una actividad de reconocida necesidad, indispensable para la vida social. En relación con la característica anterior, el concepto de servicio público trata de satisfacer una necesidad social que afecta a la mayoría de la población, reconocida previamente por el Estado.

4. Es una actividad cuya gestión no supone el ejercicio de poderes soberanos y, por tanto, no subordinada a ninguno de los poderes fáticos. Una actividad que es ajena a cualquier tipo de objetivo que no esté directa o indirectamente vinculados a la utilidad de los ciudadanos.

Para Rodríguez García, el servicio público es una técnica jurídico-administrativa que supone una mejor consecución de la protección y garantía del pluralismo dentro de la sociedad además de implicar, también, las condiciones para que la libertad e igualdad sean reales y efectivas (Rodríguez García, 1998).

El servicio público de televisión presenta unas características propias, diferentes a las de cualquier otro servicio público, dado que

"No existe ningún otro servicio que, simultáneamente, tenga un acceso tan amplio a la población, proporcione tal cantidad de informaciones y contenidos $y$, de este modo, transmita las opiniones individuales y la opinión pública e influya tanto en las mismas" (Comisión, 2001, pág. 4).

El principal escollo que presenta la aplicación de la noción de servicio público es que la definición del concepto, ampliamente configurada desde un punto de vista positivo 
Martínez Rolán, Luis Javier (2007): Espacios de divulgación científica dentro de la Televisión de servicio público: Un estudio de caso. No 14. Noviembre. Año XI.

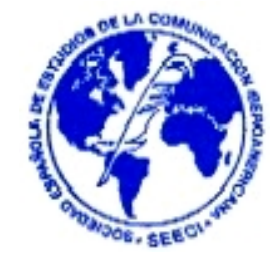

y jurídico, no suele referirse a su contenido. Es decir, señala diversas pautas genéricas donde encuadrar el servicio público -forma- pero no se arriesga a definir el objeto o ejemplo a seguir -contenido.

De este modo la noción de servicio público, al menos en el ámbito español, se queda en una expresión meramente formal que prescinde del sentido indicativo de las misiones educativas, culturales y de conservación y fomento del patrimonio de un país. En este sentido resulta interesante la reflexión de Del Corral sobre las obligaciones del servicio público,

"Un 'estatuto de servicio público' exige el reestablecimiento de obligaciones específicas, detalladas y concretas de programación y de contenidos (por ejemplo, estableciendo porcentajes de programas de determinada naturaleza que deben necesariamente emitirse, imponiendo también la franja horaria en la que esos programas deben ser emitidos, etc), tal como ocurre en el resto de los países comunitarios de nuestro entorno como Francia, Alemania o el Reino Unido". (Del Corral 2005, pág .65)

La configuración, desde la perspectiva de los contenidos, que debe presentar una televisión de servicio público generó un intenso debate dentro y fuera de las fronteras españolas. En Gran Bretaña, por ejemplo, la televisión como servicio público generó un intenso debate tanto en España como toda Europa. En Gran Bretaña, por ejemplo, además de a la célebre máxima de "informar, educar y entretener ${ }^{\prime \prime}{ }^{3}$, la noción de servicio público se vincula a los conceptos de universalidad y responsabilidad.

\footnotetext{
${ }^{3}$ Muñoz Machado (1998), haciendo referencia al caso británico, cita a Gibbons quien señala que no existe ninguna normativa anglosajona que obligue de modo expreso a la BBC a ofrecer programas educativos, regionales o para la infancia, así como los tiempos de emisión para actividades artísticas, documentales o asuntos de actualidad, por ejemplo, si bien la no presencia de estos espacios en las cadenas de la BBC sería rápidamente atacada y denunciada por no cumplir sus obligaciones.
} 


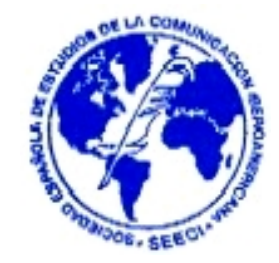

Universalidad entendida como la capacidad de llegar a todos los territorios y a una gran variedad de audiencia. Lo que significa que los programas tratarán, en la medida de lo posible, de satisfacer los intereses de las diferentes audiencias y ofrecer contenidos al gusto de los consumidores.

La responsabilidad propone que la televisión se preocupe de la información y educación de la audiencia, no sólo del entretenimiento.

Otra idea vinculada a la noción de servicio público, que se desprende de la aproximación llevada a cabo por Gorostiaga, es la de independencia. La televisión debe estar formal y sustantivamente separada de la política, sin dominios internos de valores particulares, sea cual sea el grupo de presión.

La atención a estas características a la hora de estructurar la programación de servicio público, camino a priori más difícil, exigiría una mayor creatividad, nuevas alternativas, un alto nivel de calidad y fomento del consenso cultural.

\section{La televisión autonómica gallega. La TVG.}

La aparición de las televisiones de ámbito autonómico, ámbito al que se adscribe la Televisión de Galicia (a partir de ahora TVG), había sido prevista en el artículo 2.2 del estatuto de RTVE en $1980^{4}$. Una previsión que se hizo efectiva el 26 de diciembre de 1983, con la aprobación en el parlamento de la Ley 46/1983, la denominada "Ley del Tercer Canal" (en adelante LTC); ley que autorizaba al Gobierno para tomar las

\footnotetext{
${ }^{4}$ Artículo 2.2. "El Gobierno podrá conceder a las Comunidades Autónomas, previa autorización por Ley de las Cortes Generales, la gestión directa de un canal de televisión de titularidad estatal que se cree específicamente para el ámbito territorial de cada Comunidad Autónoma".
} 
medidas pertinentes para el funcionamiento de una cadena de televisión en el ámbito territorial de cada comunidad autónoma ${ }^{5}$ (si bien en la actualidad son dos canales ${ }^{6}$ ).

La LTC también requería la creación del contexto legal oportuno para la organización y control parlamentario de los canales autonómicos que, en el caso gallego, se produciría con la Ley 9/1984 del 11 de julio, de creación de la Compañía de Radio Televisión de Galicia. Una Ley que hacía referencia a una televisión de titularidad estatal regulada por la Comunidad Autónoma Gallega, tanto en lo que respecta a la organización, control y gestión pública. Apenas dos años después de la aprobación de dicha Ley, el 24 de julio de 1985, la TVG daba inicio a sus emisiones.

En la actualidad, cuando ya han pasado más de veinte años de su puesta en marcha, la TVG (popularmente también conocida como "a Galega") ha vivido una importante transformación y ha ampliado su proyección a la "Galicia del Exterior". En efecto la Televisión de Galicia ha ampliado su radio de emisión a Europa ${ }^{7}$ y América ${ }^{8}$.

\footnotetext{
${ }^{5}$ Artículo 1

"Se autoriza al Gobierno para que tome las medidas necesarias para la puesta en funcionamiento de un tercer canale de televisión de titularidad estatal y para otorgarlo, en régimen de concesión, en el ámbito territorial de cada Comunidad Autónoma, previa solicitud de los Órganos de Gobierno de estas, y en los términos previstos en los respectivos Estatutos de autonomía, en el Estatuto de Radio y la Televisión, en sus disposiciones complementarias de orden técnico y en la presente Ley'.
}

\footnotetext{
${ }^{6}$ La ampliación a dos canales autonómicos tuvo lugar en virtud de la disposición adicional 1 de la Ley 22/1999, del 7 de junio, de modificación de la Ley 25/1994, que incorpora la directiva 89/552/CEE de Televisión sin Fonteras al ordenamiento español. En esa disposición adicional se señala que las referencias contenidos en la LTC a un tercer canal de televisión debería entenderse "aplicable a un máximo de hasta dos canales de televisión por Comunidad Autónoma, en función de las disponibilidades del espectro radioeléctrico, de acuerdo con lo establecido por el Plan Nacional de Televisión Digital Terrenal, aprobado por el Real Decreto 2169/1998, del 9 de octubre".

${ }^{7}$ La TVG comenzó sus emisiones para Europa en digital el día 7 de marzo de 1998 a través del satélite Eutelsat Hot Bird-3; pasando a ofrecer programación regular el 1 de diciembre de 1998.

${ }^{8}$ La TVG inició sus emisiones regulares para América, a través del canal Galeusca, el 31 de diciembre de 1996 a las 14.00 horas (hora local). Una emisión que, posteriormente, se efectuaría a través del satélite Hispasat (desde el 1 de diciembre de 1998). Desde el 1 de abril de 1997, a las 17.00 horas, la TVG cuenta con un canal propio para América.
} 
Asimismo, en lo que respecta a la implantación de la Televisión Digital Terrestre (TDT), la TVG comenzó a emitir con esta tecnología en marzo de 2002 desde los Centros Emisores de Pedroso (Santiago de Compostela), A Bailadora (Ares-Ferrol), Domaio (Moaña) y Tomba (Pontevedra). Emisión que cubrió una parte importante del territorio occidental gallego.

En Internet, la TVG dio comienzo a sus emisiones regulares en tiempo real el día 17 de mayo de 1997 (Día de las Letras Galegas), lo que la convirtió en la primera cadena europea y la séptima en el ámbito mundial que ofreció dicha posibilidad.

Hoy, la Televisión de Galicia emite con tecnología digital desde más de cuarenta centros emisores y reemisores que le facilitan una cobertura próxima superior al $85 \%$ de la población. Cobertura que alcanzará el $98 \%$ en abril de 2010 , cuando tenga lugar el llamado "apagón tecnológico"9.

\subsection{Legislación.}

Como cualquier canal autonómico, el funcionamiento de la Televisión de Galicia se rige por diversas normas de carácter autonómico, estatal y europeo, entre las que destaca la ya citada Ley 46/1983, del 26 de diciembre, reguladora del Tercer Canal de Televisión.

En virtud de esta Ley, el Gobierno está autorizado a tomar las medidas necesarias para la puesta en funcionamiento de un tercer canal de televisión de titularidad estatal y para otorgarlo en régimen de concesión (Artículo 1). De este primer artículo se pueden extraer dos conclusiones clave: la titularidad de la TVG pertenece al Estado español y el Gobierno gallego opera en régimen de concesión estatal.

\footnotetext{
9 Extraído de www.crtvg.es
} 
En lo relativo a la financiación de la televisión gallega dicha ley establece en el capítulo IV, artículo 17, que "la financiación del funcionamiento efectivo del tercer canal de televisión se hará mediante subvenciones consignadas en los presupuestos de las Comunidades Autónomas, la comercialización y venta de sus productos y la participación del mercado de la publicidad". Un artículo que no estipula unos límites preclaros en lo que respecta al porcentaje de financiación que compete a los presupuestos de la Comunidad Autónoma gallega ni de la cuantía relativa a los ingresos por publicidad.

Otra de las leyes que operan de forma directa sobre la televisión autonómica gallega es la Ley 25/1994 del 12 de julio, por la que se incorpora al ordenamiento jurídico español la Directiva 89/552/CEE, de televisión sin fronteras ${ }^{10}$. Ley en cuyo capítulo II, referido a la promoción, difusión y producción de determinados programas televisivos obliga a la TVG a reservar el $51 \%$ de su tiempo de emisión anual a la difusión de obras audiovisuales europeas, el $26 \%$ del cual se dedique a su emisión en expresión original en cualquier lengua del territorio español ${ }^{11}$.

\footnotetext{
10 Modificada por la Ley 22/1999, del 7 de junio, por la que se incorpora al ordenamiento español la Directiva 97/36/CE.

${ }^{11}$ El primer punto del artículo $5^{\circ}$ reza:
}

"Los operadores de televisión deberán reservar el 51 por 100 de su tiempo de emisión anual a la difusión de obras audiovisuales europeas.

Los operadores de televisión que tengan la responsabilidad editorial de canales de televisión en cuya programación se incluyan largometrajes cinematográficos de producción actual, es decir, con una antigüedad menor de siete años desde su fecha de producción, deberán destinar, como mínimo, cada año, el 5 por 100 de la cifra total de ingresos devengados durante el ejercicio anterior, conforme a su cuenta de explotación, a la financiación anticipada de la producción de largometrajes y cortometrajes cinematográficos y películas para televisión europeos, incluidos los supuestos contemplados en el art. 5.1 de la Ley de fomento y promoción de la cinematografía y del sector audiovisual. El 60 por 100 de esta financiación deberá destinarse a producciones cuya lengua original sea cualquiera de las oficiales en España.

A estos efectos se entenderá por películas para televisión las obras audiovisuales de características similares a los largometrajes cinematográficos, es decir, obras unitarias de duración superior a sesenta minutos con desenlace final, con la singularidad de que su explotación comercial no incluye la exhibición en salas de cine; y por ingresos de explotación, los derivados de la programación y explotación del canal o canales de televisión que dan origen a la obligación, reflejados en sus cuentas de explotación auditadas. 
Martínez Rolán, Luis Javier (2007): Espacios de divulgación científica dentro de la Televisión de servicio público: Un estudio de caso. No 14. Noviembre. Año XI.

Páginas 61-82

ISSN: 1576-3420 DOI: http://dx.doi.org/10.15198/seeci.2007.14.61-82

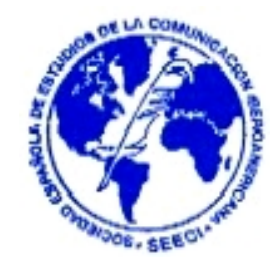

Más próximo al objeto central de este estudio se puede citar la Ley 15/2001 del 9 de julio, de fomento y promoción de la cinematografía y el sector audiovisual, que nace con el objeto de dar una normativa integral en sus aspectos de fomento y promoción, a la cinematografía y al sector audiovisual. Se trata de una ley destinada a fomentar la creación, producción y difusión e la identidad cultural de los diferentes pueblos españoles, así como la igualdad de acceso de todos los ciudadanos al conocimiento de las diferentes formas de expresión, tanto por parte de los creadores como por parte del público al que se destina, con la finalidad de lograr un enriquecimiento global del Patrimonio Cultural del sector audiovisual.

Se trata, en definitiva, de leyes que regulan la televisión como medio de comunicación social, sin prejuicio de sus aspectos técnicos, que aparecen establecidos en la Ley 31/1987, del 18 de diciembre, de Ordenación de las Telecomunicaciones.

No obstante, existe un problema a la hora de enfrentarse al servicio público de la televisión desde una perspectiva práctica, tal como señala Casado Salinas (2005, pág. 161):

"[...] la democracia que supuso la adaptación de la radiotelevisión pública al nuevo sistema político mediante la Ley 4/1980, de Estatuto de la Radio y Televisión, en lo educativo no supuso nada, más centrados los legisladores en superar de alguna manera el origen dictatorial de RTVE, poniéndola formalmente bajo el control del Parlamento y olvidando establecer claramente las obligaciones del servicio público, como las establecidas por el Parlamento británico para la $B B C$ por ejemplo. Inmediatamente se amplió en España el 
Martínez Rolán, Luis Javier (2007): Espacios de divulgación científica dentro de la Televisión de servicio público: Un estudio de caso. No 14. Noviembre. Año XI.

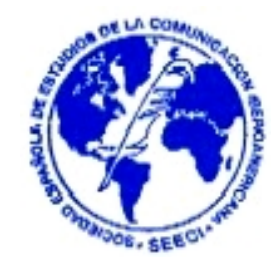

servicio público con las autonómicas y posteriormente, la prioridad en toda Europa fue creación de televisiones privadas, perdiendo las públicas, el monopolio del que habian disfrutado hasta entonces, con lo que lo educativo fue de nuevo relegado, más preocupados sus gestores en sobrevivir en el nuevo entorno competitivo y con financiación insuficiente".

Circunstancia que deja entrever que, más allá de los puros hechos formales y financieros, en el ámbito de los contenidos audiovisuales la noción de servicio público pierde nitidez con facilidad.

\section{Contenidos de calidad en la TVG. Un ejemplo de divulgación científica.}

Cuando se hace referencia a los contenidos que deben configurar una televisión de servicio público, una de las características que se cita con mayor frecuencia es la calidad. Una calidad cuya definición resulta a priori compleja debido a la propia esencia del término.

Para Moragas y Prado (2001) la calidad en televisión se corresponde con el desarrollo de un tratamiento informativo orientado por criterios profesionales que den apoyo al pluralismo político, social y cultural, que permita establecer una serie de mecanismos capaces de garantizar la independencia. Pero también es calidad la preservación de parcelas informativas, más allá de la espectacularización televisiva, con la intención de favorecer la formación de un criterio sobre los temas de relevancia para la sociedad; la elaboración programas de análisis sobre temas complejos para facilitar su comprensión a la población, o nuevas formas de tratamiento informativo que consigan la atención del público sin desvirtuar los contenidos; o la oferta de contenidos de interés para determinados sectores o colectivos de la población como 
Martínez Rolán, Luis Javier (2007): Espacios de divulgación científica dentro de la

Televisión de servicio público: Un estudio de caso. No 14. Noviembre. Año XI.

Páginas 61-82

ISSN: 1576-3420 DOI: http://dx.doi.org/10.15198/seeci.2007.14.61-82

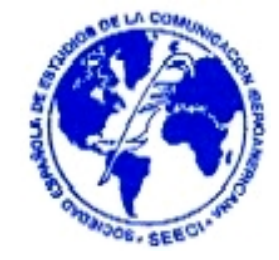

los programas sobre minorías; o la creación de las condiciones que favorezcan la creatividad, la programación de propuestas innovadoras en franjas de máxima audiencia y su mantenimiento el tiempo preciso para la adaptación de la audiencia.

De cualquier modo, la calidad emerge como una exigencia fundamental del servicio público televisivo. Exigencia que se hace particularmente patente en las cadenas de titularidad pública en las que, siguiendo a Moragas y Prado (2001), coexisten dos concepciones diferentes de televisión: la que ejerce un rol subsidiario con una oferta de contenidos que, dado su público minoritario y elevado coste, sería impensable en las cadenas privadas; y la que detenta un rol protagonista con una programación destinada al público general que garantiza una cuota de penetración amplia, permitiéndole cumplir una serie de objetivos como servicio público.

Esta dupla concepción de la televisión, que en los sistemas de televisión pública [estatal] en Europa es asumida por dos cadenas diferentes: la primera de carácter generalista y la segunda de rol subsidiario ${ }^{12}$, en el ámbito de la TVG ésta debe conjugar y vehicular ambas vertientes. De este modo la televisión gallega ofrece una programación de interés general, como los informativos de proximidad (autonómicos y comarcales), programas de entretenimiento como Luar (programa de variedades con importante componente de música gallega), Acompáñenos (magazine vespertino) o series de ficción como Libro de Familia o la veterana Platos combinados. Una programación que es conjugada con otros contenidos de carácter subsidiario que asumen la función formativa- cultural de la televisión de servicio público, con programas como Hai debate! (debate político o de actualidad), Miraxes (magazine artístico-cultural), Volver ao Rego (comentario de actualidad), Labranza y O Agro (información-divulgación agrícola y ganadera); o que trazan una oferta de entretenimiento más minoritaria como Luba TV (espacio que conjuga deporte -liga

\footnotetext{
12 Es el caso de TVE1 y La 2, en España, RTP1 y RTP2, en Portugal, France 2 y France 3, en Francia, RAI1 y RAI2 en Italia, etc.
} 
Martínez Rolán, Luis Javier (2007): Espacios de divulgación científica dentro de la

Televisión de servicio público: Un estudio de caso. No 14. Noviembre. Año XI.

Páginas 61-82

ISSN: 1576-3420 DOI: http://dx.doi.org/10.15198/seeci.2007.14.61-82

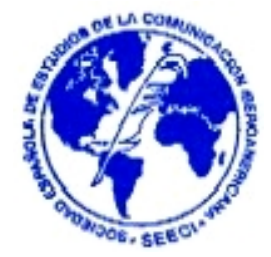

universitaria de baloncesto- con música, artes escénicas y humor de jóvenes promesas gallegas).

Precisamente, esta tipología de programación de carácter subsidiario que vehicula la TVG resulta particularmente interesante desde la perspectiva del objeto de estudio. Un objeto, el estudio de caso de un programa de divulgación científica Ciencianosa, que fue abordado desde una perspectiva de análisis de contenido complementada con una entrevista con el Director de dicho espacio: Xosé Durán.

\subsection{Ciencianosa y el mundo científico gallego.}

Ciencianosa es un programa semanal de la Televisión de Galicia, de media hora de duración, destinado a la divulgación científica. Un espacio que da comienzo a su emisión el 12 de agosto de 2006 con una vocación clara: transmitir el mensaje de que la Ciencia, en particular la desarrollada en Galicia, puede resultar divertida en cuanto se puede explicar con parámetros sencillos y mostrar su aplicación práctica.

La filosofía de Ciencianosa es la de explicar los acontecimientos científicos a padres e hijos, a abuelos y nietos, a expertos y profanos, siempre con la ilusión de que las explicaciones puedan servir para suscitar el interés pro la ciencia y despertar vocaciones científicas entre los más jóvenes.

Cada programa incluye cinco sesiones que se presentan en plató con los redactores y asesores científicos como conductores directos de la información científica:

- Galiciencia. Reportaje sobre un grupo de investigadores gallego, pertenecientes a la institución universitaria como a otros organismos de investigación de carácter público o privado.

El tejido investigador gallego está compuesto por decenas de grupos de investigación, algunos de los cuáles con líneas de investigación destacables aunque poco conocidas y apreciadas por el gran público. 


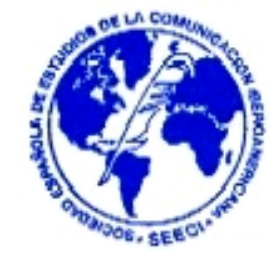

Esta sección adapta su nombre a la tipología de contenidos y áreas de trabajo en las que se centra. De hecho, si la investigación está centrada en el ámbito de la medicina o de la farmacia, esta sección pasa a denominarse Saude (salud); Novas Tecnoloxías (nuevas tecnologías) si trata aspectos relativos a los nuevos campos tecnológicos; Con-ciencia Ecolóxica (Con-ciencia ecológica) si se refiere a le ecología o al medio ambiente, etc.

- Curioso Mundo Científico. Sección en la que el profesor Jorge Mira ${ }^{13}$, asesor científico del programa, explica alguna investigación en el campo de las ciencias experimentales, de las ciencias de la salud o incluso de las Ciencias Sociales, que puedan despertar la curiosidad de los telespectadores. En definitiva, aquellos estudios científicos que precisen de una explicación.

- O Gran Paso. En esta sección se pretende explicar a la audiencia alguno de los grandes descubrimientos o avances científicos de todos los tiempos, o aquellas investigaciones de mayor calado científico.

El código genético, la conquista espacial, la teoría de la evolución, el funcionamiento de las vacunas, el origen de la especie humana e incluso el control de los fraudes científicos son algunos de los contenidos de esta sección.

- In-nova. Breve sección centrada en el trabajo de investigación y quehacer diario de un investigador que tenga un contrato Parga Pondal o Ramón y Cajal, u otro tipo de investigadores contratados por el CSIC o por aquellas empresas que cuenten con un programa de $\mathrm{I}+\mathrm{D}+\mathrm{i}$.

\footnotetext{
13 Profesor del Departamento de Física Aplicada de la Universidade de Santiago de Compostela. Colaborador con diversos programas de la Televisión de Galicia.
} 
En apenas tres minutos, estos investigadores vocacionales explican el por qué han seleccionado una profesión que no les garantiza su futuro a largo plazo.

- Telesabio. En esta sección, desarrollada en el propio plató, el profesor Jorge Mira explica algún experimento o responde a aluna pregunta básica de Ciencia. Por ejemplo, por qudicos, q siempre desde un punto mlas investigaciones gallegas al gran $\mathrm{p}$ configura el equipo del programa, con la funcicuanto sé vuelan los aviones o por qué flotan los barcos.

En definitiva, se trata de un programa de divulgación científica para todos los públicos que pretende cumplir, tal como asegura el propio equipo humano que configura el equipo del programa, con la función de la televisión como servicio público. De facto, Ciencianosa da a conocer las investigaciones gallegas al gran público pero siempre desde una perspectiva lúdica, capaz de producirles la sensación de descubrir algo nuevo, sensación que transmiten los propios investigadores participantes.

Además de la divulgación científica propiamente dicha, este programa está enfocado -como un objetivo secundario- a suscitar en los más jóvenes una actitud diferente hacia la ciencia; actitud que permita el nacimiento de nuevas vocaciones científicas en la sociedad gallega.

Ciencianosa no busca un público determinado a priori. Como programa para todos los públicos pretende interesar a los espectadores de televisión en general, sin importar su perfil. A pesar de que, el propio equipo del programa contaba con la idea preconcebida de que un programa de divulgación científica no resultaría atractivo para determinados sectores del público como amas de casa o jubilados. Una idea que les llevó a considerar, en el diseño inicial del programa, un target compuesto por chicos/as y/o jóvenes con estudios, o con curiosidad hacia determinados aspectos del ámbito científico. 


\section{REVISTA DE LA SEECI}

Martínez Rolán, Luis Javier (2007): Espacios de divulgación científica dentro de la Televisión de servicio público: Un estudio de caso. No 14. Noviembre. Año XI.

Páginas 61-82

ISSN: 1576-3420 DOI: http://dx.doi.org/10.15198/seeci.2007.14.61-82

Sin embargo, durante el análisis del esquema y dinámica del programa, se percataron de que los contenidos de divulgación científica se encuentran, en la prensa generalista, dentro del apartado "sociedad".

De este modo, los contenidos de este programa están encaminados a hacer asequible la ciencia a los diversos públicos, especialmente desde la perspectiva de su utilidad en los hábitos, actuaciones y preferencias de los telespectadores, sin distinción de edad, perfil psicológico o ubicación urbana o rural.

\subsection{Ciencianosa como parte de la programación de servicio público.}

Siguiendo a Xosé Durán ${ }^{14}$, director del programa, Ciencianosa forma parte de la programación de servicio público de la Televisión de Galicia porque

"[...] Primeiro por que son programas de servizo público e segundo que son programas divertidos. A televisión hai que recoñecer que debe conxugar o factor diversión co factor aprendizaxe ou mostrar algo, en definitiva, comunicar, que a televisión é un medio de comunicación. Podes comunicar de maneira máis alegre e máis desenfadada, podes facelo con contidos menos conceptuais ou podes divulgar cun contido máis rotundo. Hai que ter en conta que $o$ público ao que vas é un público moi heteroxéneo e que non é demasiado específico. Se fora esto o que buscamos deberíamos estar nunca canle específica. Se fora unha canle de ciencia, faríamos algo concreto para ese público que, seguramente, terá unha base formativa moito máis ampla. No caso dunha televisión xeneralista como é a TVG, e un público galego con menos formación científica, pois hai que buscar programas moi divulgativos pero moi divertidos".

\footnotetext{
${ }^{14}$ En entrevista con el autor.
} 


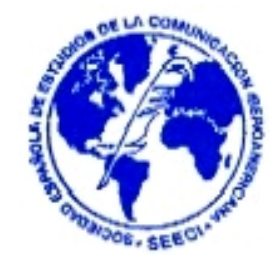

Se trata de un programa que, partiendo de la idea de que la ciencia puede ser entretenida, conjuga la divulgación científica con el entretenimiento: juega con experimentos vistosos y curiosos, por ejemplo, para llamar la atención del espectador sin obviar la función más educativa, con explicaciones y reportajes sobre la ciencia actual (que continúa siendo la base del programa).

Xosé Duran también pone de relevancia una clara razón por la que Ciencianosa puede ser considerada de servicio público: su relación con las identidades.

"O servizo público pódese facer de calquera maneira pero, ao fin e ao cabo, é o que vale e vela polo interese xeral da sociedade moitas veces, incluso, para autoidentificarse, son así e son de aqui" (Xosé Durán).

Se trata de potenciar "lo gallego", en este caso utilizando como base la producción científica Made in Galicia: líneas de investigación, grupos, investigadores, etc.

Ciencianosa es un programa que nace de un cambio, como afirma Xosé Durán, de una apuesta fuerte por parte de la dirección de la TVG por una serie de formatos más informativos y divulgativos. Una apuesta fruto de una particular sensibilidad que encuentra su momento [año 2006] y su lugar [TVG].

En lo que se refiere a la participación, Ciencianosa se encuadra más en una idea tradicional de la misma: un equipo de programa que investiga y propone una serie de contenidos, en lugar de ser la audiencia la que aporta ideas para el programa.

No obstante, su buen acogimiento por la comunidad científica gallega junto a la satisfacción causada, reportó al programa el apoyo de dicha comunidad; circunstancia que para el equipo del programa resultó un reconocimiento más que loable. 


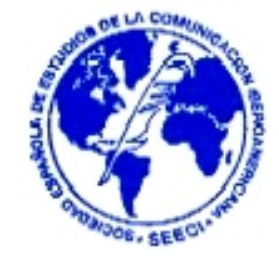

La novedad que introduce Ciencianosa es la participación en dos niveles del mundo científico y del universitario; dos ámbitos tradicionalmente olvidados por el medio audiovisual que, tal como reflejan sus índices de audiencia (próximos al promedio de la cadena) presentan muy buena acogida entre la audiencia.

\section{Conclusiones.}

El análisis de la noción de servicio público en la televisión y su formulación práctica presenta algunas divergencias que, de algún modo, está relacionada con la ausencia de referencias al tipo de contenidos que deben estar presentes en dicha programación. Si bien existe consenso de todos los actores implicados a la hora de definir la calidad como elemento imprescindible en los contenidos de servicio público. Una calidad en ocasiones vinculada a una concepción de televisión de élites y que, desde la perspectiva de la clásica premisa de informar, formar y entretener, dejaría huérfano al público mayoritario. En efecto, tal y como se ha podido observar, resulta posible desarrollar una programación de servicio público para una mayoría de espectadores.

Si la promoción de identidades culturales, particularmente las denominadas "valiosas" por Salcedo Megales (2001), está implícita en la función del servicio público de la televisión, en la Televisión de Galicia dado su enfoque hacia una colectividad concreta (los gallegos), dicha promoción se hace completamente indispensable. De este modo la TVG está destinada a promover una serie de contenidos que potencien la lengua y los rasgos culturales propios de la comunidad gallega.

Otra cuestión que es preciso tener en cuenta es que la televisión, como agente socializador, precisa de una ética que conjugue la rentabilidad económica con aquella de carácter social, en términos de utilidad para la ciudadanía. Una rentabilidad que, 
si bien parece difícil de conseguir a priori, sí que es posible tal como se puede desprender del estudio de caso llevado a cabo.

El análisis de Ciencianosa, programa de divulgación científica de la TVG, atendiendo a aquellos parámetros estipulados para el servicio público de televisión, pone de relevancia su pertenencia a esta tipología de espacios que -si bien se ajusta a la concepción de una televisión de calidad- presenta resultados de audiencia favorables. El propio director del programa, Xosé Durán, destaca la importancia para una programación de servicio público de encontrar el punto medio entre el entretenimiento y la formación. Un equilibrio que permita, como en este caso, realizar divulgación científica pero de un modo ágil, dinámico y plural: ciencia para todos.

En definitiva, este trabajo demuestra la posibilidad de conjugar positivamente la lógica empresarial y la función de servicio en una fórmula de éxito, sin que ninguna de las dos prime sobre la otra de manera intrusiva, reforzando la tesis de que, en el contexto de televisión actual - donde la calidad es una característica a la baja -, otra televisión sí es posible.

\section{Bibliografía}

AIMC (2006): "Resumen del Estudio General de Medios". Disponible en www.aimc.es/-Datos-EGM-Resumen-General-.html. Consultado el 14/4/2006.

BOE:

- Ley 15/2001, de 9 de julio, de fomento y promoción de la cinematografía y el sector audiovisual. 
- Ley 25/1994, de 12 de julio, por la que se incorpora al Ordenamiento Jurídico Español la Directiva 89/552/CEE, sobre la coordinación de Disposiciones Legales, Reglamentarias y Administrativas de los Estados Miembros relativas al ejercicio de actividades de Radiodifusión Televisiva.

- Ley 31/1987, del 18 de diciembre, de Ordenación de las Telecomunicaciones

- Ley 4/1980, de 10 de enero, de Estatuto de la Radio y la Televisión. (Vigente hasta el 7 de junio de 2006), en: Boletín Oficial del Estado, no 11, del 12 de enero de 1980.

- Ley 46/1983, de 26 de diciembre, reguladora del Tercer Canal de Televisión, en: Boletín Oficial del Estado, no 4, del 5 de enero de 1984.

- Ley 9/1984 del 11 de julio, de creación de la Compañía de Radio Televisión de Galicia.

CASADO SALINAS, Juan María (2005): El servicio público de la televisión. Universidad de Granada. Granada.

DEL CORRAL, Jorge (2005): "El futuro de las televisones públicas" en GARCÍA CASANOVA, Juan Francisco y CASADO SALINAS, Juan María (Eds.): El servicio público de la televisión. Editorial Universidad de Granada. Granada

Directiva 89/552/CEE de 3 de octubre de 1989, sobre la coordinación de determinadas disposiciones legales, reglamentarias y administrativas de los Estados Miembros relativas al ejercicio de actividades de radiodifusión televisiva.

GOROSTIAGA, Eduardo (1982): El Estatuto de la Radio y la Televisión. Forja. Madrid. 
GRUPO CORPORACIÓN MULTIMEDIA (2007): "La audiencia en televisión en 2006" Disponible en: http://200.2.115.237/IMG/pdf/anual 2006 final.pdf. Consultado el $\underline{02 / 01 / 2007 .}$

MINISTERIO DE INDUSTRIA, TURISMO Y COMERCIO (2004): Comunicación de la Comisión sobre la aplicación de las normas en materia de ayudas estatales a los servicios públicos de radiodifusión (2001/C 320/04). Madrid

MORAGAS, M. y PRADO, E. (2001): "Repensar la televisión pública en el contexto digital" en Portal de Comunicación de la Comunición. Disponible en www.portalcomunicacion.com/observa/polis/tvp.pdf. Consultado 17/04/2006.

MUÑOZ MACHADO, Santiago (1998): Servicio público y mercado, Vol III. Ed. Civitas. Madrid.

RODRIGUEZ GARCÍA, José Antonio (1998): El control de los medios de comunicación: participación de los grupos idológicos en el control de los medios de comunicación. Ed. Dykinson Centro Eniversitario Ramón Carande. Madrid.

SALDECO MEGALES, Damián (2001): "¿Tiene el Estado la obligación de desarrollar una cultura de la identidad personal?' en Telos, revista iberoamericana de estudios utilitaristas, Volumen IX, número 1, SIEV Salamanca.

\section{Webgrafía}

Compañía de Radio Televisión de Galicia (TVG): www.crtvg.es. 